Boletín de la Sociedad Geológica Mexicana

VOLUMEN 63, NÚM. 1, 2011, P. 119-135

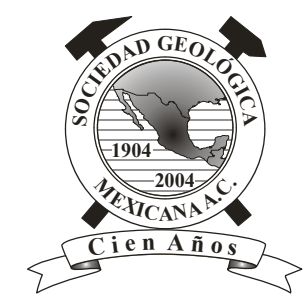

\title{
Metodología para la definición de unidades hidroestratigráficas: caso del acuífero del valle del río Yaqui, Sonora, México
}

\author{
Rogelio Monreal ${ }^{1},{ }^{*}$, Miguel Rangel-Medina ${ }^{1,2, *}$, Adrián Grijalva-Montoya ${ }^{2}$, Ismael Minjarez- \\ Sosa $^{1}$, Mariano Morales-Montaño ${ }^{1}$ \\ ${ }^{1}$ Departamento de Geología, Universidad de Sonora, Blvd. Luis Encinas y Av. Rosales, Hermosillo, Sonora, 83000. \\ ${ }^{2}$ IDEAS, Investigación y Desarrollo de Acuíferos y Ambiente, Hermosillo, Sonora, México. \\ *monreal@geologia.uson.mx
}

\section{Resumen}

En este trabajo se propone una metodología para definir unidades hidroestratigráficas y se analizan algunas definiciones de unidades hidroestratigráficas preexistentes. Sin embargo, no existe una definición aceptada ampliamente por lo que el presente trabajo se propone definir las unidades hidroestratigráficas usando las características litológicas de los sedimentos y los valores de conductividad hidráulica. Se propone una metodología para la definición de unidades hidroestratigráficas en acuíferos granulares. Se presenta el caso del acuífero del valle del río Yaqui y se definen las unidades hidroestratigráficas con base en las características de los sedimentos que rellenan la cuenca que corresponde a ambientes sedimentarios fluviales. Se identificó la existencia de las cinco unidades hidroestratigráficas que constituyen el acuífero. También, con la interpretación de la hidroestratigrafía, se pudieron determinar los tipos de sedimentos existentes a diferentes profundidades reconociendo la presencia del antiguo cauce del río Yaqui.

Palabras clave: unidad hidroestratigráfica, metodología, modelo conceptual hidrogeológico.

\begin{abstract}
A method for defining hydrostratigraphic units is herein proposed, and various definitions of hydrostratigraphic units previously proposed are analyzed. Nevertheless, none of the definitions are widely accepted; therefore, the hydrostratigraphic units proposed here are defined using the lithologic characteristics of the sediments along with the values of hydraulic conductivity. A methodology to define hydrostratigraphic units in granular aquifers is proposed. The case of the Yaqui River aquifer is analyzed here and the hydrostratigraphic units are defined based on the characteristics of the sediments filling the basin, which correspond to fluvial sedimentary environments. Five hydrostratigraphic units were identified in the aquifer. Also, with the interpretation of the hydrostratigraphy, it was possible to determine the kind sediments present at different depths, thereby recognizing the presence of the ancient river channel of the Yaqui River.
\end{abstract}

Keywords: hydrostratigraphic unit, methodology, hydrogeologic model. 


\section{Introducción}

Los hidrogeólogos durante mucho tiempo han observado que el flujo de agua subterránea a menudo no está relacionado con los límites de las unidades estratigráficas estándares. Los términos hidrogeológicos "acuífero" y "unidad hidroestratigráfica" son comúnmente utilizados para subdividir el subsuelo en unidades relacionadas con la hidrología de agua subterránea. Sin embargo, el término "acuífero" comúnmente se usa para definir el abastecimiento de agua en términos económicos como un adjetivo erróneo. En México, "acuífero" es comúnmente definido por convención administrativa y aparece en leyes y reglamentos locales de tal forma que hace difícil utilizar "acuífero" como un término técnico y menos aún científico, además de que, en ocasiones, es confundido con el término de "cuenca" (NRC, 1995; Antuna-Ibarra y Kretzschmar, 2004; Badan et al., 2006; Herrera-Carbajal et al., 2007). Por ejemplo, en la Ley de Aguas Nacionales (Artículo 3 , fracción II) un acuífero se define como "cualquier formación geológica o conjunto de formaciones geológicas hidráulicamente conectados entre sí, por las que circulan o se almacenan aguas del subsuelo que pueden ser extraídas para su explotación, uso o aprovechamiento y cuyos límites laterales y verticales se definen convencionalmente para fines de evaluación, manejo y administración de las aguas nacionales del subsuelo". Sin embargo, no define el término de unidad hidroestratigráfica y probablemente la Ley de Aguas Nacionales considera acuífero y unidad hidrogeológica como sinónimos.

El conocimiento y uso de un sistema de aguas subterráneas requiere una comprensión de los factores hidrogeológicos que controlan el almacenamiento y transporte en el subsuelo del agua subterránea. Sin embargo, sabemos que los medios saturados se encuentran en cuencas rellenas por sedimentos que constituyen medios geológicos heterogéneos, por lo que la comprensión de transporte y almacenamiento subterráneo del agua es una difícil tarea. Por ello es importante el conocimiento de la estratigrafía (en este caso la hidroestratigrafía) de la cuenca en donde se encuentra el acuífero que es materia de estudio, y ayuda en la comprensión del movimiento del flujo y almacenamiento del agua subterránea. Sin embargo, existen muy pocos trabajos que utilicen el término de unidad hidroestratigráfica (i.e. Monreal et al., 2001; Copeland et al., 2009; Sanz et al., 2009).

En este trabajo se presenta un estudio estratigráfico del acuífero del valle del río Yaqui en donde se establecen las unidades hidroestratigráficas y se presenta una metodología de trabajo para su establecimiento.

\section{Definición de unidad hidroestratigráfica}

El concepto de unidad hidroestratigráfica fue originalmente definido por Maxey (1964) como un cuerpo de roca de extensión considerable que forma parte de un esquema geológico con un sistema hidrológico distintivo, y como unidad fundamental para describir sistemas hidrogeológicos en el campo basada en las propiedades de las rocas que afectan las condiciones del agua subterránea. Maxey (1964) identificó la necesidad de definir unidades de agua subterránea basadas, no sólo en las características litológicas específicas, sino también en la dinámica del régimen hidrogeológico incluyendo parámetros aplicables especialmente al movimiento de agua, su ocurrencia y almacenamiento. Sin embargo, debido a que estos atributos no son propiedades materiales de las rocas, la definición de Maxey (1964) no puede ser usada en concordancia con el Código Estratigráfico Norteamericano (NACSN, 2005), ya que éste estipula que las unidades litoestratigráficas deben estar basadas en contenido, límites y atributos físicos, como características líticas y posición estratigráfica.

Existe desacuerdo entre hidrogeólogos tanto para cartografiar y nombrar sistemas de flujo y cuerpos de roca separadamente como para encontrar la manera de combinar los dos conceptos en un solo sistema de cartografía y nomenclatura (Seaber, 1988). Mucho de este desacuerdo en la clasificación y nomenclatura de unidades hidroestratigráficas se debe a que la naturaleza de los límites de las unidades no ha sido definida antes de obtener su cartografía. Seaber $(1986,1988)$ definió una unidad hidroestratigráfica como un cuerpo de roca que se distingue por su porosidad y permeabilidad y consideró que esta definición está más de acuerdo con las reglas de nomenclatura estratigráfica (Salvador, 1994; NACSN, 2005) y con la idea de que las unidades hidroestratigráficas pueden presentarse en una o más unidades litoestratigráficas, aloestratigráficas, pedoestratigráficas o litodémicas, y son unificadas y delimitadas con base en sus características hidrológicas observables y que se relacionan con sus intersticios. Seaber $(1986,1988)$ también definió a las unidades hidroestratigráficas por el número, tamaño, forma, arreglo e interrelación de sus intersticios, y son reconocidas con base en la naturaleza, extensión, y magnitud de los intersticios en una roca sedimentaria, metamórfica o ígnea.

Por otro lado, Fetter (1994) define a la unidad hidroestratigráfica como una formación, parte de una formación o grupo de formaciones en las que existen características hidrológicas similares que permiten agruparlas en acuíferos o capas confinantes y constituidas por unidades geológicas agrupadas con base en su conductividad hidráulica similar. Además, especifica que los acuíferos estratificados están especialmente presentes en cuencas sedimentarias compuestas de unidades hidroestratigráficas individuales con diferentes conductividades hidráulicas.

Además, Poehls y Smith (2009) consideran que una unidad hidroestratigráfica es lo mismo que una unidad hidrogeológica y la definen como una o más unidades geológicas de amplia extensión lateral que se distinguen de los cuerpos de roca o sedimentos que la rodean y relacionadas por medio de parámetros hidrológicos 
similares como la conductividad hidráulica. Poehls y Smith (2009) mencionan que el límite hidroestratigráfico puede correlacionarse o no con el límite de una formación, por lo que puede resultar en varias formaciones incluidas en una unidad hidroestratigráfica tal como un acuífero, o una sola formación puede ser dividida en varias unidades hidroestratigráficas; por ejemplo, acuíferos múltiples con sus capas confinantes relacionadas.

Sin embargo, Copeland et al. (2009) definen una unidad hidroestratigráfica como un cuerpo de roca distinguido y caracterizado por su porosidad y permeabilidad, unificada y delimitada con base en sus características hidrológicas observables relacionadas con sus intersticios. Indican que los dos términos, tanto "unidad hidroestratigráfica" como "unidad hidrogeológica" son aceptables, pero que el primero es preferible.

Como se puede apreciar, existen varias maneras de definir unidades hidroestratigráficas y hasta ahora no existe una definición consensuada o ampliamente aceptada. Por lo anterior, en el presente trabajo las unidades hidroestratigráficas se definieron con base en lo propuesto por Poehls y Smith (2009), quienes las distinguen a partir de la litología y parámetros hidrológicos como la conductividad hidráulica, por lo que para este trabajo se usaron las características litológicas de los sedimentos recuperados en los pozos, y a cada unidad se le asignó un valor de conductividad hidráulica, obtenida a partir de las pruebas de bombeo, asociando de esta manera los valores hidráulicos y geoeléctricos a cada tipo de litología.

\section{Una metodología para el establecimiento de unidades hidroestratigráficas}

Al parecer, no existe una metodología propuesta para establecer unidades hidroestratigráficas, ya que en los trabajos donde se tratan o definen este tipo de unidades no se presenta alguna metodología propuesta (Maxey, 1964; Seaber, 1988; Fetter, 1994; Hawley et al., 2001; Paula e Silva et al., 2005; Copeland et al., 2009; Poehls y Smith, 2009; Sanz et al., 2009). En este estudio se propone una metodología para la definición de unidades hidroestratigráficas que consiste de varias etapas. Los pasos propuestos en esta metodología se resumen en la Figura 1.

La metodología usada para la definición de unidades hidroestratigráficas se divide en tres partes: (1) definición de la estratigrafía y paquetes litológicos presentes, (2) definición de las propiedades hidrogeológicas de los paquetes litológicos, y (3) agrupamiento y reagrupamiento de los paquetes litológicos con base en sus propiedades hidrogeológicas. A continuación se presenta una descripción más detallada de cada paso.

\subsection{Descripción de la estratigrafía y paquetes litológicos}

a) Recopilación de mapas y bases topográficas, imágenes satelitales, fotografías aéreas y modelos digitales de terreno, información geológica del área de estudio (estratigrafía superficial y subterránea, mapas geológicos, estructurales, y geomorfológicos). Con esta información se elaboran mapas geológicos del área de estudio, se identifican las unidades litológicas sedimentarias que pudieran estar presentes en el subsuelo, se identifican las estructuras regionales que pudieran afectar el área de estudio y, en particular, al relleno sedimentario de la cuenca.

b) Análisis de la litología de los pozos en el área de estudio, análisis granulométricos de cada pozo. Por cada pozo se separan intervalos a diferente profundidad con litología y granulometría similar, estableciendo así las unidades litológicas para cada pozo.

c) Homogenización de las unidades litológicas establecidas para cada pozo y, eventualmente, en superficie, con el fin de permitir la comparación y correlación entre éstos.

d) Elaboración de secciones litológicas por medio de correlaciones entre pozos seleccionados, estableciendo correspondencia entre las diferentes unidades litológicas para cada sección, permitiendo establecer por medio de varias secciones perpendiculares las principales unidades litoestratigráficas para el área de estudio.

3.2 Definición de las propiedades hidrogeológicas de los paquetes litológicos

a) Uso de pruebas de bombeo para la evaluación de las propiedades hidrogeológicas de los paquetes litológicos como permeabilidad y conductividad hidráulica.

b) Análisis granulométrico de las muestras de las perforaciones de pozos para establecer porosidad y valores de conductividad de tablas estandarizadas.

c) Análisis de información de registros geofísicos para la evaluación indirecta de la conductividad hidráulica. La resistividad es una de las propiedades de las rocas más comúnmente usadas en la interpretación de registros, por medio de ella se pueden determinar parámetros importantes de los materiales del subsuelo y de los acuíferos, tales como la porosidad, saturación del fluido, anomalías presentes y calidad del agua, entre otros.

d) Si se cuenta con información de Sondeos Eléctricos Verticales (SEV), se pueden establecer unidades geoeléctricas a partir del agrupamiento de paquetes definidos en los registros geofísicos de pozos, que pueden ser correlacionados con base en las propiedades hidrogeológicas inferidas.

3.3 Agrupamiento y reagrupamiento de los paquetes litológicos con base en sus propiedades hidrogeológicas

a) Se establecen las unidades hidrogeológicas con base en el agrupamiento de paquetes litológicos a partir de las propiedades hidrogeológicas evaluadas o inferidas (normalmente, la conductividad hidráulica). 


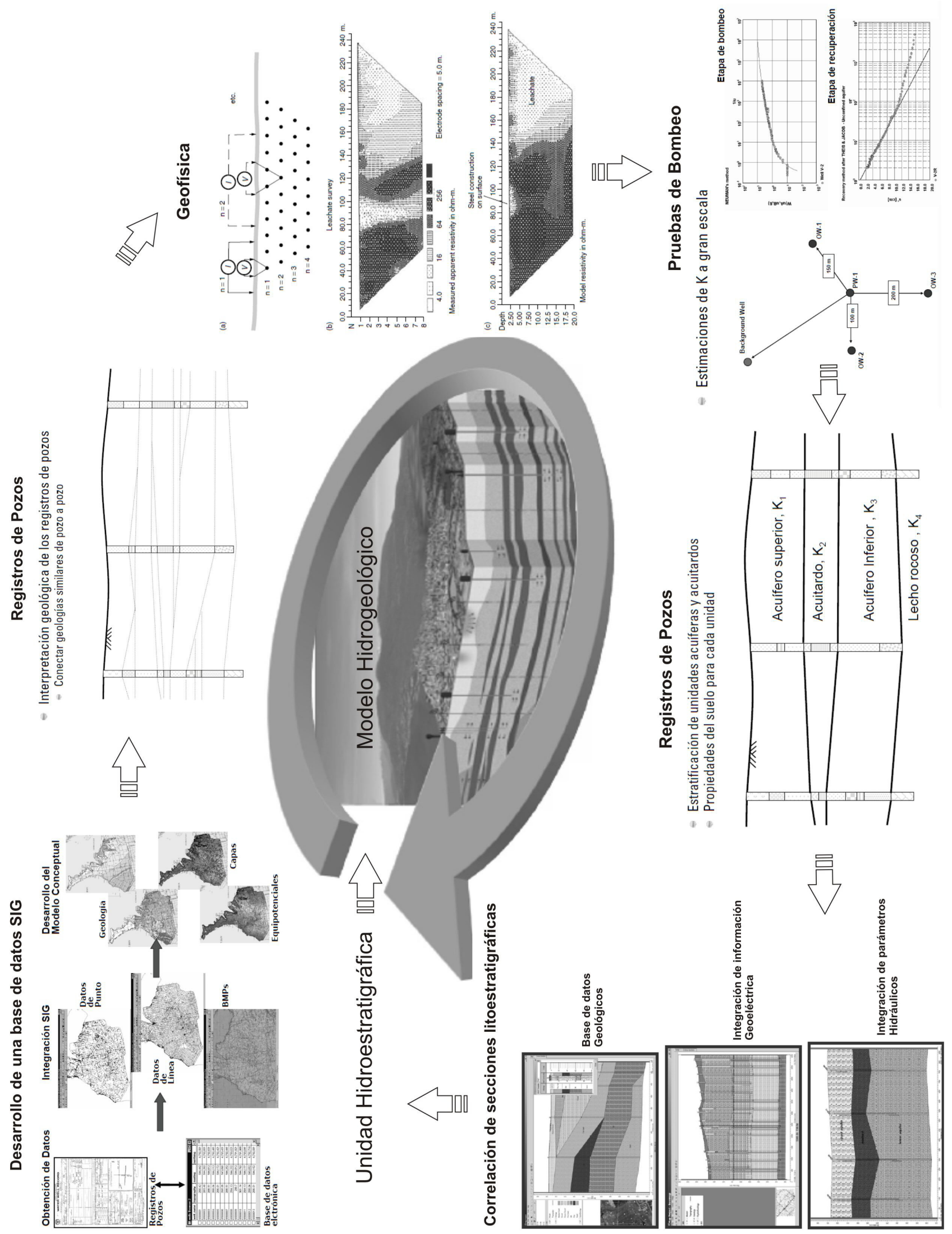

Figura 1. Diagrama que muestra la metodología propuesta para el establecimiento de unidades hidroestratigráficas. 
b) Una vez realizado esto, se definen las características físicas distintivas de cada unidad: contenido litológico (homogéneo o heterogéneo), límites verticales y límites horizontales y, finalmente, el nombre de la unidad en caso que así se desee. Para este último se recomienda que se utilicen las directrices definidas en las reglas de nomenclatura estratigráfica (Salvador, 1994; NACSN, 2005).

Finalmente, con la ayuda de un SIG, toda la información generada e interpretada se resume en un modelo hidrogeológico esquemático tridimensional que contiene información sobre el funcionamiento hidrogeológico de la zona de estudio.

\section{El acuífero del valle del río Yaqui}

El valle del río Yaqui, una de las zonas de producción agrícola más importante del país, se encuentra situado en la parte sur del estado de Sonora, entre los paralelos $27^{\circ} 00^{\prime}$ y $27^{\circ} 40^{\prime}$ de latitud Norte y entre los meridianos $109^{\circ} 40^{\prime}$ y $110^{\circ} 25^{\prime}$ de longitud Oeste. Su extensión aproximada es de $5000 \mathrm{~km}^{2}$ (Figura 2). El área de estudio se localiza dentro de la porción baja de la cuenca hidrológica baja del río Yaqui, formando parte de la compleja distribución de las planicies fluvio-aluviales y deltaicas del río. Dichos ambientes han determinado la amplia variedad de sedimentos con diferentes características hidrogeológicas del subsuelo. Dentro del área de estudio están incluidos los acuíferos denominados valle del río Yaqui y una porción del acuífero denominado Cocoraque, de acuerdo con los límites de acuíferos establecidos por la Comisión Nacional del Agua. La mayor superficie del distrito de riego del río Yaqui y la actividad agrícola principal se cubre parcialmente con el agua subterránea de estos dos acuíferos.

El río Yaqui ha sido, a través de los años, el principal vehículo de transporte del material reciente de relleno del valle, cuya principal fuente de material proviene de las rocas que rodean la enorme cuenca, principalmente de la parte norte, y rellena con sus depósitos aluviales los cauces que se han prolongado hasta la costa. En el valle, el acuífero ha sido alimentado por las infiltraciones del río Yaqui, de los

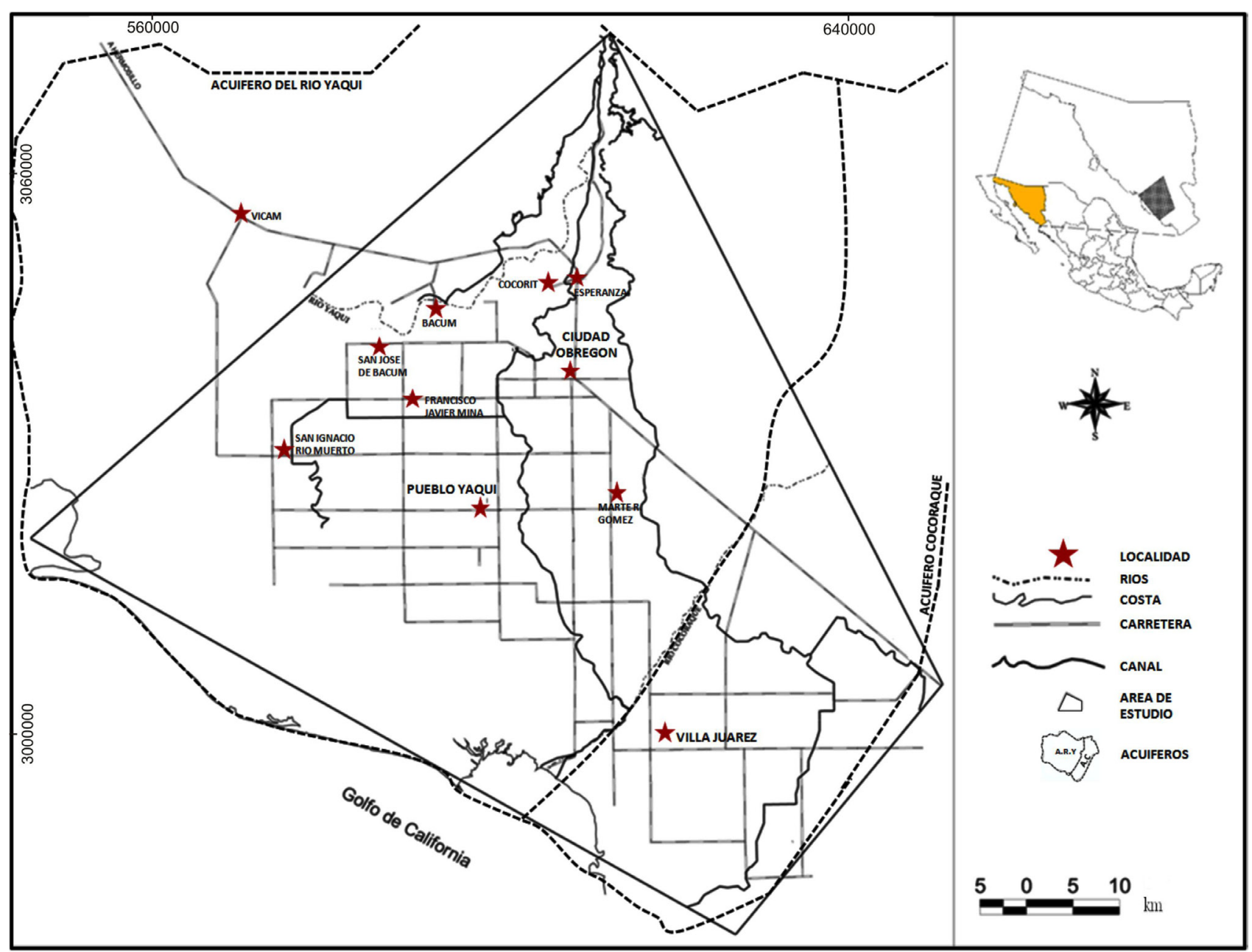

Figura 2. Localización del área de estudio del acuífero de valle del río Yaqui. 
canales artificiales y las filtraciones del agua de riego vertida en los suelos agrícolas, produciéndose así una recarga total inducida de $646.73 \mathrm{Hm}^{3}$ (Monreal et al., 2003).

Aunque se han llevado a cabo algunos trabajos que aportan información para entender las condiciones hidrológicas del valle y las geohidrológicas del acuífero (ICATEC Consultores, 1970; Geólogos Consultores Asociados, S.A., 1979; Canales y Díaz, 1986; GómezAldama, 1992; Lozano-Cota, 1992; Instituto Tecnológico de Sonora, 1996, 2000; Técnicas Geológicas y Mineras, 1996, 1997; Ansaldo-Leyva, 1999; Zapuche-Moreno, 2000; Flores-Tapiz, 2001; Navarro-Ibarra, 2001; GutiérrezHeredia, 2004), sólo los trabajos de Martínez-Uribe (1999) y Monreal et al. (2003) presentan información, aunque limitada, y definen y presentan descripciones generalizadas de las unidades estratigráficas que componen los acuíferos estudiados.

En este trabajo se definen las unidades hidroestratigráficas que componen el acuífero y sus características, mediante el análisis de la litología y correlaciones litoestratigráficas de los pozos, para contribuir a la actualización del modelo conceptual hidrogeológico del acuífero del valle del río Yaqui.

\subsection{Geología del valle del río Yaqui}

Dentro del área de estudio en el valle del río Yaqui, existen unidades estratigráficas cuyas edades varían desde el Cretácico Inferior hasta el Holoceno, y la nomenclatura tanto formal como informal que se utiliza para las unidades estratigráficas está basada principalmente en los trabajos realizados por el Servicio Geológico Mexicano. A continuación se enlistan las unidades que afloran en el área de estudio, de la más antigua a la más reciente (MinjarezSosa et al., 2002; García-Cortés y Siqueiros-López 2002; Figura 3): batolitos Laramídicos (KBL), volcanismo riolítico de la Sierra Madre Occidental (Tvr), volcanismo intermedio de dacita-andesita (TVi), Formación Báucarit (TFMB), y depósitos recientes (Qal). A continuación se presentan descripciones generales de estas unidades.

Batolitos Laramídicos (KBL): Los intrusivos que se incluyen dentro de esta denominación corresponden a dos grupos bien diferenciados. El primero está constituido por granitos y granodioritas con texturas faneríticas equigranulares $\mathrm{y}$, a partir de fechamientos radiométricos, se ubican en un rango de edad entre el Cretácico Tardío y el Eoceno (Grijalva-Noriega y Roldán-Quintana, 1998). El segundo grupo corresponde a intrusivos de composición diorítica que fueron emplazados durante el Eoceno. La mayoría de estos cuerpos ígneos se presentan en forma de troncos o batolitos de dimensiones kilométricas y tienen una amplia distribución en el área de estudio, generalmente con afloramientos alineados con una dirección NNW-SSE (Minjarez-Sosa et al., 2002).

Volcanismo riolítico de la Sierra Madre Occidental (Tvr): En esta unidad se agrupan todas las rocas volcánicas y piroclásticas de composición ácida con basaltos en la parte superior, que afloran principalmente en la porción septentrional de la Sierra Madre Occidental en Sonora. La base de este grupo está dominada por una secuencia piroclástica de tobas riolíticas e ignimbritas, que incluye lahares y brechas volcánicas de composición ácida. También incluye rocas detríticas, representadas por capas de conglomerados polimícticos donde dominan clastos subredondeados de andesita, así como capas medianas a gruesas de areniscas tobáceas. La porción superior de esta unidad la conforman dos diferentes secuencias volcánicas que cubren a la secuencia basal: tobas riolíticas y andesíticas a andesitas basálticas, y flujos y brechas basálticas (Minjarez-Sosa et al., 2002).

Volcanismo intermedio dacítico-andesítico (TVi): Incluye rocas volcánicas y volcaniclásticas de composición intermedia, compuestas por intercalaciones de areniscas tobáceas, tobas ácidas y riolitas de estratificación de mediana a delgada. Asimismo, dentro de la secuencia también hay rocas volcánicas de composición intermedia, característicamente andesitas y tobas andesíticas. También incluye una secuencia detrítica dominada por conglomerados polimícticos donde dominan clastos subangulosos de andesita, así como areniscas conglomeráticas de aspecto tobáceo (Minjarez-Sosa et al., 2002).

Formación Báucarit (TFMB): En esta unidad se incluye una serie de rocas sedimentarias y volcánicas del Mioceno dominadas por conglomerados polimícticos, cuyos clastos son dominantemente subangulosos y subredondeados, y están constituidos por rocas volcánicas e intrusivas. Intercaladas con capas de conglomerado se encuentran algunas capas de estratificación mediana a gruesa de areniscas de grano grueso a conglomeráticas. Formando parte de esta secuencia también se encuentran basaltos y andesitas basálticas intercaladas con rocas detríticas. También incluyen areniscas tobáceas y tobas riolíticas intercaladas en capas de estratificación mediana a gruesa, así como riolitas de textura fluidal y amigdalar (MinjarezSosa et al., 2002).

Depósitos recientes (Qal): Esta unidad incluye sedimentos recientes principalmente a lo largo de los cauces de los ríos y arroyos mayores del área de estudio, así como en sus porciones costeras y suroccidental. De manera general, estos sedimentos corresponden principalmente a gravas y arenas de diferente granulometría y composición, así como capas de lodo en algunas localidades, que se relacionan a la actividad reciente netamente fluvial, o bien al desarrollo de complejos deltaicos en la porción costera. En esta unidad también se incluyen sedimentos que cubren las áreas de cultivo en el valle de río Yaqui (Minjarez-Sosa et al., 2002).

Por medio de levantamientos gravimétricos se puede definir la configuración o profundidad del basamento y, con ello, el espesor del relleno sedimentario, por lo que se realizó un levantamiento gravimétrico en el área de estudio, que consistió en 14 secciones gravimétricas. La 


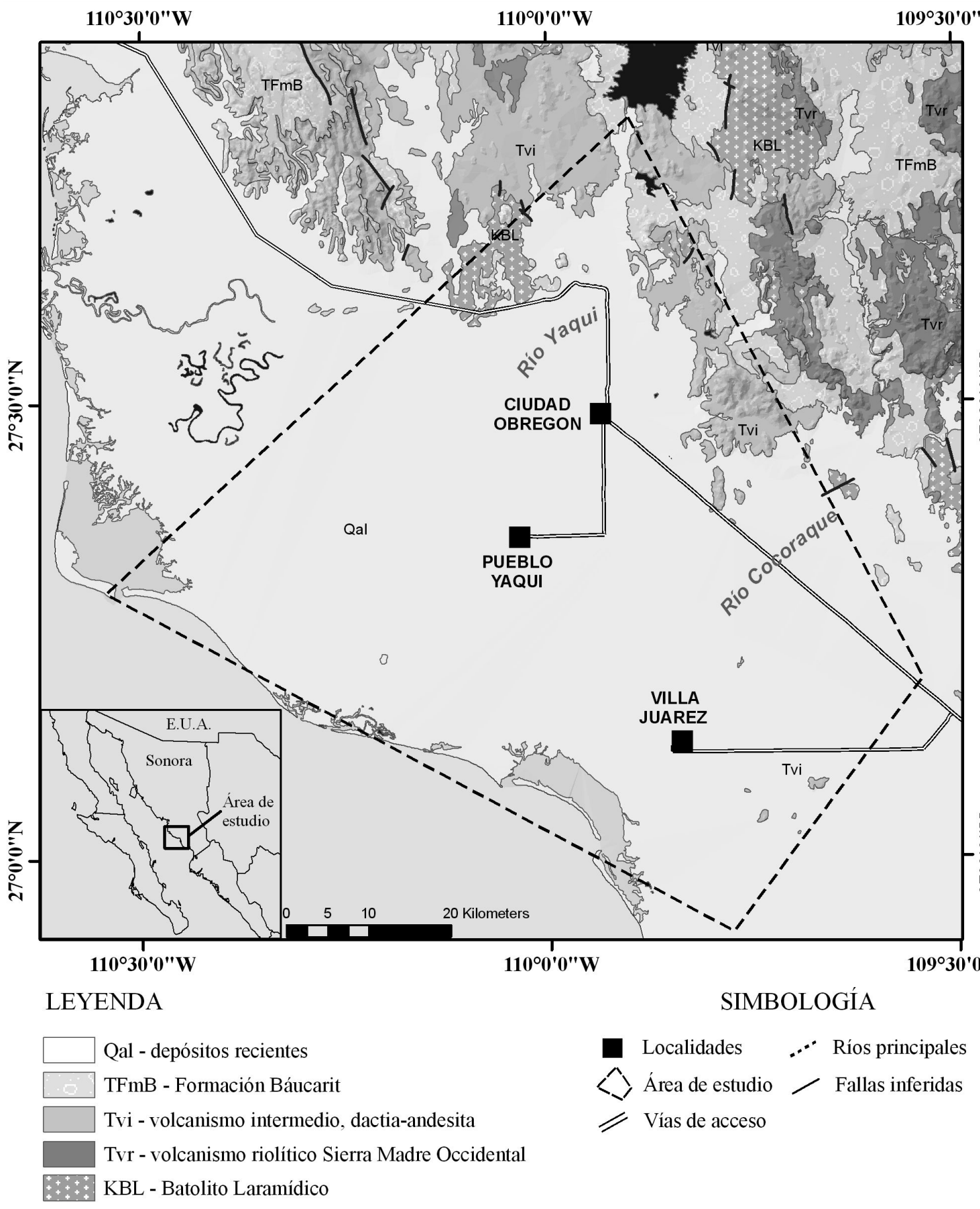

Figura 3. Mapa geológico de valle del río Yaqui (tomado de García-Cortéz y Siqueiros-López 2002; Minjarez-Sosa et al., 2002).

información obtenida en este estudio permite deducir que los espesores de los materiales de relleno superan los 1000 $\mathrm{m}$, pero el espesor del acuífero es de 200 a $300 \mathrm{~m}$. También se detectó la ubicación de tres fosas o bajos topográficos, posiblemente producidas por fallamiento vertical: (1) una pequeña depresión ubicada por debajo del cauce actual del río Yaqui; (2) una gran depresión o fosa en la parte central del valle, orientada N-S, por debajo de la calle 5 de Febrero en la parte central del área de estudio, y (3) una fosa que pierde continuidad hacia el suroeste y sólo en los niveles freáticos someros se conecta con la fosa anterior, en la porción sureste del área de estudio, por debajo del arroyo Cocoraque (Figura 4). La fosa central podría estar asociada con una falla importante en el basamento, con reactivaciones posteriores que afectaron al relleno sedimentario. Como se mostrará más adelante, algunas de estas fallas se evidencian 


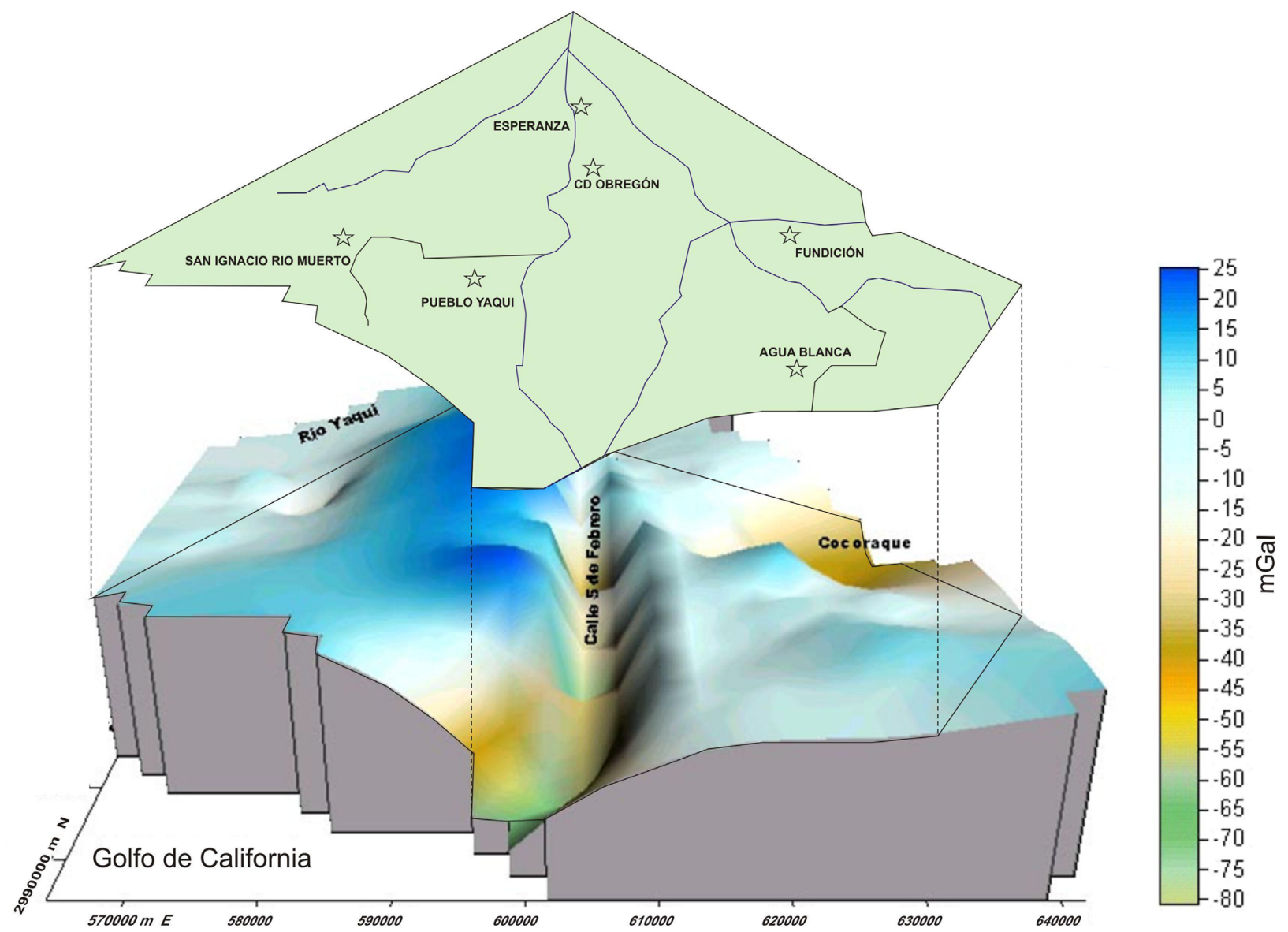

Figura 4. Bloque tridimensional de anomalías de Bouguer en el valle del río Yaqui.

en el relleno sedimentario, desplazando algunas unidades hidroestratigráficas.

Con base en la información obtenida de cortes litológicos de pozos se identificó que la litología del subsuelo consta de diferentes niveles de estratos constituidos por grava y arena de alta permeabilidad, arena fina de media permeabilidad, arena arcillosa, limo y arcilla de baja permeabilidad y arcilla de muy baja permeabilidad. Con base en un análisis detallado de las litologías de los pozos se infiere que estos sedimentos corresponden a ambientes sedimentarios fluviales.

\subsection{Hidrogeología del acuífero del valle del Yaqui}

El espesor de los sedimentos que confinan el sistema acuífero es del orden de los $200 \mathrm{~m}$ a $300 \mathrm{~m}$, con un sistema hidráulico compuesto por dos acuíferos independientes. El más somero de tipo libre (freático), se encuentra en la zona próxima a la superficie, por arriba de los $150 \mathrm{~m}$ de profundidad, denominado aquí acuífero superior y, por debajo de éste, se encuentra un acuífero regional de amplia extensión y de espesor y composición variable, que varía de tipo libre, a semiconfinado y confinado.

El acuífero superior está formado por relleno reciente con niveles freáticos someros, es de baja transmisividad, no cubre totalmente al acuífero regional y no es homogéneo. El acuífero superior está formado por sedimentos cuaternarios de grano mediano a fino que alterna con abundantes lentes de arcilla. Por debajo de estos sedimentos se encuentra el acuífero regional, constituido por material sedimentario semi-consolidado, de muy baja permeabilidad y que contiene agua salobre y/o salina.

La zona vadosa que cubre al acuífero superior varía en espesor, tiene un carácter generalmente antropogénico moderno, alterado por la intensa actividad de la agricultura y responde hidráulicamente como medio anisotrópico. $\mathrm{Su}$ conocimiento es importante para entender el mecanismo de recarga por infiltración vertical y la vulnerabilidad a la contaminación del acuífero freático. En el área de estudio existen 4 tipos de texturas de suelos, siendo los arcillosos los más ampliamente distribuidos. Se han reportado velocidades de infiltración del orden de $0.123 \mathrm{~m} / \mathrm{a}$ (Verduzco, 2002), esto significa que a una recarga local desde los canales o drenes, o bien del retorno de riego le podría tomar años atravesar la zona vadosa para alcanzar un nivel freático somero de entre 2 y $7 \mathrm{~m}$ de profundidad.

En el acuífero superior, las áreas más importantes desde el punto de vista hidrogeológico para captación 
y almacenamiento de agua subterránea son los cauces abandonados del antiguo río Yaqui que depositó lentes de grava de espesores decamétricos, de alta conductividad hidráulica y, por lo tanto, de muy alto rendimiento. Dado que el nivel freático del acuífero superior es muy somero, es altamente vulnerable a la contaminación en zonas específicas, puesto que en este tipo de acuíferos se pueden presentar fenómenos de ascensión capilar del agua a la zona de aireación por una evaporación activa proveniente del suelo, de aquí su salinización. Sin embargo, el acuífero no se extiende en todo el valle, se presenta sólo por áreas de diversos tamaños, dado que fue originado en forma de relleno sedimentario de zonas topográficamente bajas, por lo que presenta múltiples acuñamientos, de aquí la variedad de sus sedimentos tanto en espesores como en textura y la amplia variación en permeabilidad vertical y horizontal (Monreal et al., 2003).

Este acuífero yace sobre estratos arcillosos a limoarcillosos no consolidados de baja permeabilidad, de espesor variable, con múltiples acuñamientos a través de los cuales el tránsito de la recarga vertical fluye lentamente mientras se infiltra, ya sea desde el acuífero superior, directamente de las superficies de riego, de los canales, de los drenes no revestidos o pobremente revestidos. A diferentes profundidades, el agua puede quedar atrapada sin moverse por largos periodos.

El acuífero regional se encuentra en todo el valle, pero puede encontrarse también de tipo libre. De aquí que, en general, se le ha considerado como de tipo semiconfinado, puesto que en algunas localidades los estratos arcillosos actúan como estratos impermeables. Los espesores del acuífero regional son muy variables, y el espesor máximo observado en los perfiles de pozos es de $250 \mathrm{~m}$. Sin embargo, en ellos no se muestra que el basamento se encuentre al final del pozo. No obstante, con los estudios geofísicos realizados, así como con la descripción de perfiles de múltiples pozos, se definió su geometría permitiendo reconocer su textura y un espesor promedio de $300 \mathrm{~m}$. La textura y la estructura de los materiales que constituyen el acuífero regional varían lateralmente, lo cual se refleja en los valores de transmisividad. La variedad de valores de parámetros hidráulicos lo ubican como libre, semiconfinado y confinado, dependiendo del sitio donde se haya realizado la prueba de bombeo (Monreal et al., 2003).

\subsection{Hidroestratigrafía del acuífero del valle del Yaqui}

\subsubsection{Unidades hidroestratigráficas}

Las unidades hidroestratigráficas definen las características del relleno sedimentario de la cuenca y los límites espaciales de las zonas acuíferas en sentido lateral y vertical. Estas unidades han sido propuestas con base en datos de litología de pozos seleccionados y de correlaciones litológicas llevadas a cabo en este estudio. Con esta información se identificó la existencia de 5 unidades hidroestratigraficas que constituyen el acuífero. La Tabla 1 muestra algunas de las características de cada una de las unidades establecidas, y los valores de conductividad hidráulica fueron estimados con base en pruebas de aforo y bombeo así como en su litología.

4.3.1.1. Unidad 1. Esta unidad comprende las capas superiores de sedimentos que cubren el valle del río Yaqui, consistente principalmente de arcillas de color café, de baja permeabilidad y de espesores que varían entre 1 y 20 $\mathrm{m}$. El rango de conductividad hidráulica de la unidad es de $10^{-7}$ a $10^{-8} \mathrm{~m} / \mathrm{s}$.

4.3.1.2. Unidad 2. Esta unidad es netamente fluvio-aluvial y está constituida principalmente por sedimentos no consolidados de arena, arena arcillosa y, ocasionalmente, arcilla de color café y gravilla. La arena varía de grano

Tabla 1. Propiedades de las unidades hidroestratigráficas del acuífero del valle del río Yaqui.

\begin{tabular}{|c|c|c|c|c|c|}
\hline Unidad & Litología principal & $\begin{array}{c}\text { Rango de } \\
\text { conductividades } \\
\text { hidráulicas } \\
(\mathrm{m} / \mathrm{s})\end{array}$ & $\begin{array}{c}\text { Rango de } \\
\text { resistividad } \\
(\mathrm{Ohm} / \mathrm{m})\end{array}$ & Espesor & Ambiente \\
\hline 1 & Arcillas & $10^{-7}$ a $10^{-8}$ & $1-4$ & $1-20 \mathrm{~m}$ & Fluvial \\
\hline 2 & $\begin{array}{l}\text { Arena, arena arcillosa, arcilla y } \\
\text { gravilla }\end{array}$ & $10^{-3}$ a $10^{-4}$ & $18-32$ & $20-200 \mathrm{~m}$ & Fluvio-aluvial \\
\hline 3 & $\begin{array}{c}\text { Arena, grava, boleo, gravilla y } \\
\text { ocasional arcilla }\end{array}$ & $10^{-4}$ a $10^{-5}$ & $8-15$ & $20-180 \mathrm{~m}$ & Fluvial \\
\hline 4 & $\begin{array}{c}\text { Arena, arena arcillosa, gravilla y } \\
\text { ocasional arcilla }\end{array}$ & $10^{-3}$ a $10^{-5}$ & $6-12$ & $15-150 \mathrm{~m}$ & Fluvio-aluvial \\
\hline 5 & $\begin{array}{c}\text { Arena, grava, gravilla, arena arcillosa } \\
\text { y arcilla }\end{array}$ & $10^{-3}$ a $10^{-4}$ & $16-30$ & $50-150 \mathrm{~m}$ & Aluvial-fluvial \\
\hline Basamento & Granito y roca volcánica & $10^{-12}$ a $10^{-14}$ & $200-1000$ & Desconocido & Ígneo intrusivo \\
\hline
\end{tabular}


fino a medio y está conformada por granos de cuarzo, fragmentos de rocas, muscovita y biotita. Esta unidad inicia cerca de la superficie $(3 \mathrm{~m}$ ) hasta $195 \mathrm{~m}$ de profundidad y presenta espesores que varían de $20 \mathrm{~m}$ a $200 \mathrm{~m}$. El rango de conductividad hidráulica de la unidad es de $10^{-3}$ a $10^{-4} \mathrm{~m} / \mathrm{s}$.

4.3.1.3. Unidad 3. Está constituida por un paquete de sedimentos formado por complejos fluviales, principalmente con arenas, gravas, boleos, gravillas, y ocasionalmente por arenas arcillosas y arcillas de color café. La arena varía de grano fino a medio y grueso, y está conformada por granos de cuarzo, fragmentos de roca, muscovita y biotita. Esta unidad se encuentra desde 20 a $230 \mathrm{~m}$ de profundidad, con espesores que varían entre 20 y $180 \mathrm{~m}$. La geometría de este medio granular muestra un sistema compuesto por horizontes de sedimentos detríticos de espesores variables que constituyen lentes acuíferos libres, semiconfinados y confinados. La fuerte presencia local de inter-estratos semiconfinantes puede restringir el movimiento lateral y vertical del flujo subterráneo, disminuyendo su velocidad. El rango de conductividad hidráulica de la unidad es de $10^{-4}$ a $10^{-5} \mathrm{~m} / \mathrm{s}$.

4.3.1.4. Unidad 4. Está constituida por sedimentos no consolidados característicos de depósitos fluvio-aluviales, consistentes en arena, arena arcillosa, gravilla y ocasionales depósitos arcillosos, originados en lagunas costeras aisladas, evidenciados por paquetes de espesores considerables de arcilla (60 a $140 \mathrm{~m}$ ). La parte más somera de esta unidad se encuentra a $80 \mathrm{~m}$ de profundidad, y la parte más profunda a $250 \mathrm{~m}$. Su espesor varía de 15 a $150 \mathrm{~m}$. El rango de conductividad hidráulica de la unidad es de $10^{-3}$ a $10^{-4} \mathrm{~m} / \mathrm{s}$.

4.3.1.5. Unidad 5. Está constituida principalmente por arenas, gravas, gravilla, ocasionalmente por arenas arcillosas y arcillas. Corresponde posiblemente a sedimentos característicos de ambientes desde aluviales, depositados en las laderas de antiguos cerros y sedimentos fluviales depositados por paleocanales. El nivel más somero de esta unidad se encuentra a $115 \mathrm{~m}$ y la máxima profundidad a 260 $\mathrm{m}$, su espesor varía de 50 a $150 \mathrm{~m}$. El rango de conductividad hidráulica de la unidad es de $10^{-3}$ a $10^{-4} \mathrm{~m} / \mathrm{s}$.

4.3.1.6. Basamento. Esta unidad se considera el basamento de la cuenca que corresponde a rocas graníticas y volcánicas, y se ha detectado en algunos pozos a 100, 164, 180 y 240 $\mathrm{m}$ de profundidad.

\subsubsection{Secciones hidroestratigráficas}

En el área de estudio se realizaron 7 secciones hidroestratigráficas, 3 paralelas a la línea de costa, con una orientación NW-SE y aproximadamente de unos $60 \mathrm{~km}$ de longitud, y 4 secciones perpendiculares a la costa, con una orientación SW-NE y con longitudes que varían de 16 a 28 $\mathrm{km}$ (Figura 5). En dichas secciones se muestran las unidades hidroestratigráficas propuestas para el acuífero del valle del río Yaqui, y descritas en el apartado anterior.
4.3.2.1. Sección 1. Esta sección de $28 \mathrm{~km}$ de longitud está orientada más o menos perpendicular a la línea de costa con una orientación W-E, y la constituyen las Unidades 1, 2 y 3 (Figura 6). La Unidad 1 presenta espesores de 2 a $15 \mathrm{~m}$. En general la Unidad 2 tiene espesores que varían de 10 a $45 \mathrm{~m}$, y hasta $190 \mathrm{~m}$. Como se puede observar en la Figura 6, la Unidad 2 presenta mayores espesores en la parte este de la sección, y un lente de grava de aproximadamente 12 $\mathrm{m}$ de espesor, que posiblemente corresponde a paleocauces del antiguo río Yaqui. En la Unidad 3 se encuentra también un intervalo de grava de aproximadamente $30 \mathrm{~m}$ de espesor, y un lente de arena arcillosa con un espesor de $35 \mathrm{~m}$. En general la Unidad 3 tiene espesores máximos perforados que varían entre 40 y $180 \mathrm{~m}$.

La diferencia de espesores en la Unidad 2 indica la presencia de una falla con orientación Norte-Sur, ubicada entre los pozos P43 y P127, y que produjo el hundimiento del bloque oriental de la falla, lo cual originó un profundo graben que fue rellenado por los sedimentos de la Unidad 2. Este graben corresponde a la fosa localizada por debajo de la Calle 5 de Febrero, localizada en el centro del área de estudio (Figura 3).

4.3.2.2. Sección 2. La sección 2, de $31 \mathrm{~km}$ de longitud, está orientada casi perpendicularmente a la línea de costa (orientación SW-NE) y compuesta por las Unidades 1, 2 y 3 (Figura 7). La Unidad 1 presenta espesores entre $<2$ y $10 \mathrm{~m}$. La Unidad 2 presenta un espesor entre 88 y $190 \mathrm{~m}$ y contiene lentes de arenas arcillosas entre 30 y $66 \mathrm{~m}$ de espesor, así como pequeños lentes de gravas. La Unidad 3 presente espesores máximos perforados entre 68 y $142 \mathrm{~m}$ (Figura 7).

Se evidencia la presencia de una falla con orientación $\mathrm{N}-\mathrm{S}$ entre los pozos P28 y P54, que produjo el hundimieto del bloque noreste en la sección, resultando un profundo graben que fue rellenado por los sedimentos de la Unidad 2. Este graben corresponde con la fosa localizada por debajo de la Calle 5 de Febrero (Figura 3).

4.3.2.3. Sección 3. Esta sección de $19 \mathrm{~km}$ de longitud, orientada SW-NE, está constituida por las Unidades 1, 2, 3, 4 y 5 (Figura 8). La Unidad 1 presenta espesores entre < 2 y $20 \mathrm{~m}$. La Unidad 2 tiene espesores entre 54 y $86 \mathrm{~m}$, y contiene un lente de arenas arcillosas de $30 \mathrm{~m}$ de espesor. La Unidad 3 presenta espesores variables entre 15 y $80 \mathrm{~m}$. También en esta unidad se encuentra un paquete de arenas arcillosas con un espesor de $\sim 40 \mathrm{~m}$. La Unidad 4 varía en espesor entre 85 y $148 \mathrm{~m}$. También contiene un intervalo irregular de 40 a $50 \mathrm{~m}$ de espesor de arenas de grano fino a medio. Se observa un depósito arcilloso compactado de 70 a $150 \mathrm{~m}$ de espesor con pequeñas intercalaciones de arenas finas. En el noreste de la sección y en la base de esta unidad se observa un lente de arenas arcillosas de $50 \mathrm{~m}$ de espesor. La Unidad 5 en la base de la sección presenta un límite superior irregular y un espesor máximo perforado de $42 \mathrm{~m}$. 


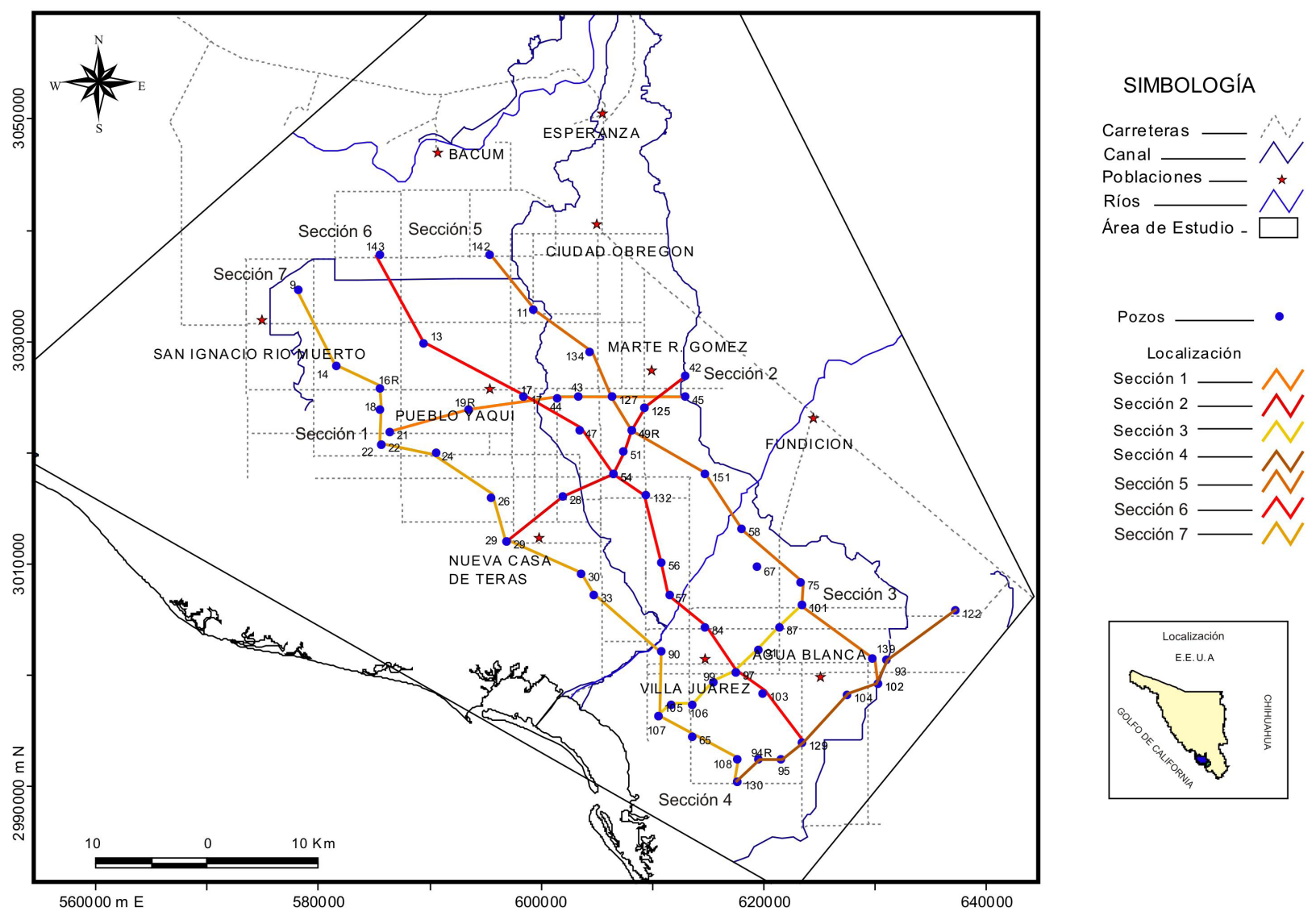

Figura 5. Localización de secciones estratigráficas en el área del valle del río Yaqui.

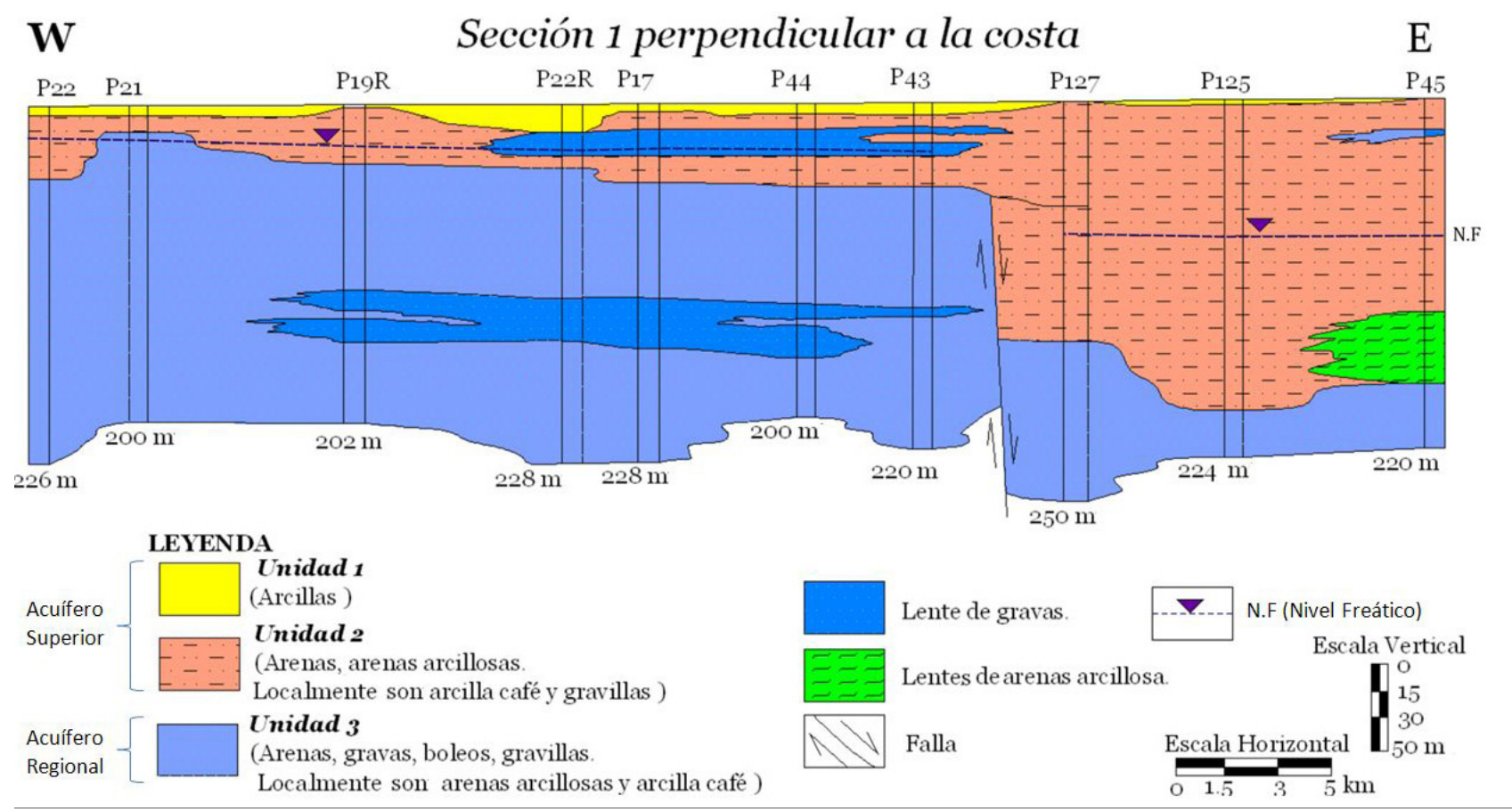

Figura 6. Sección 1 perpendicular a la línea de costa orientada W-E. 


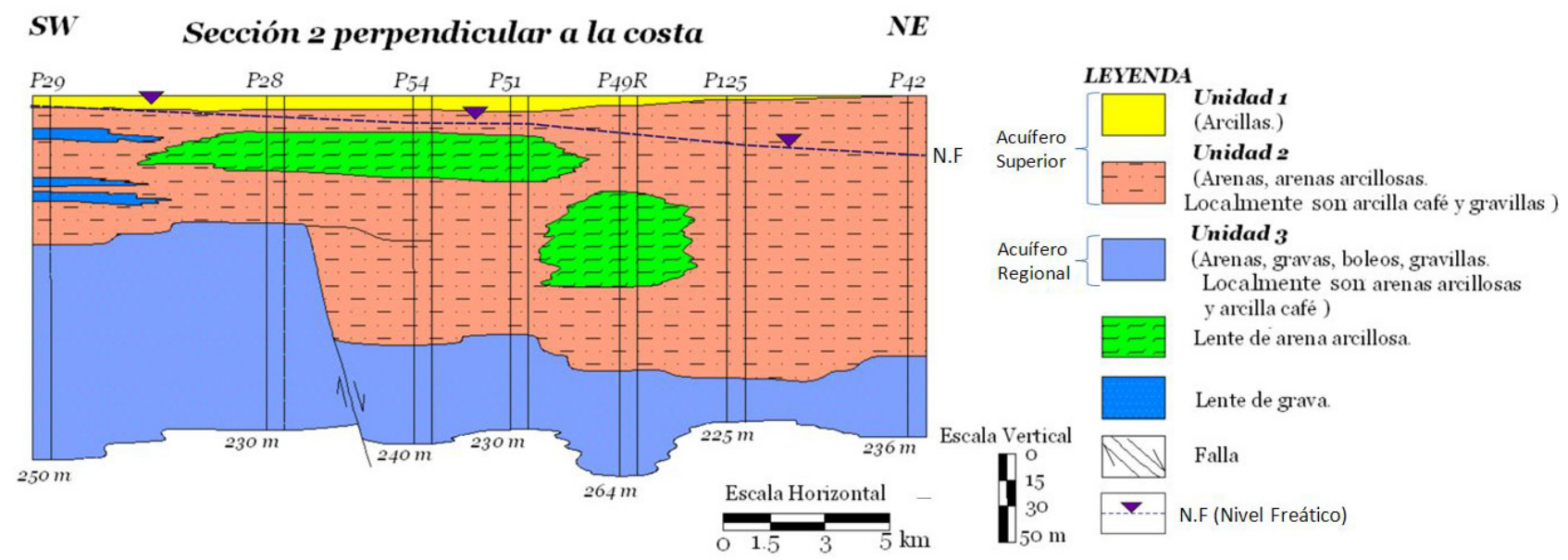

Figura 7. Sección 2 perpendicular a la línea de costa orientada SW-NE.

\section{SW Sección 3 perpendicular a la costa NE}
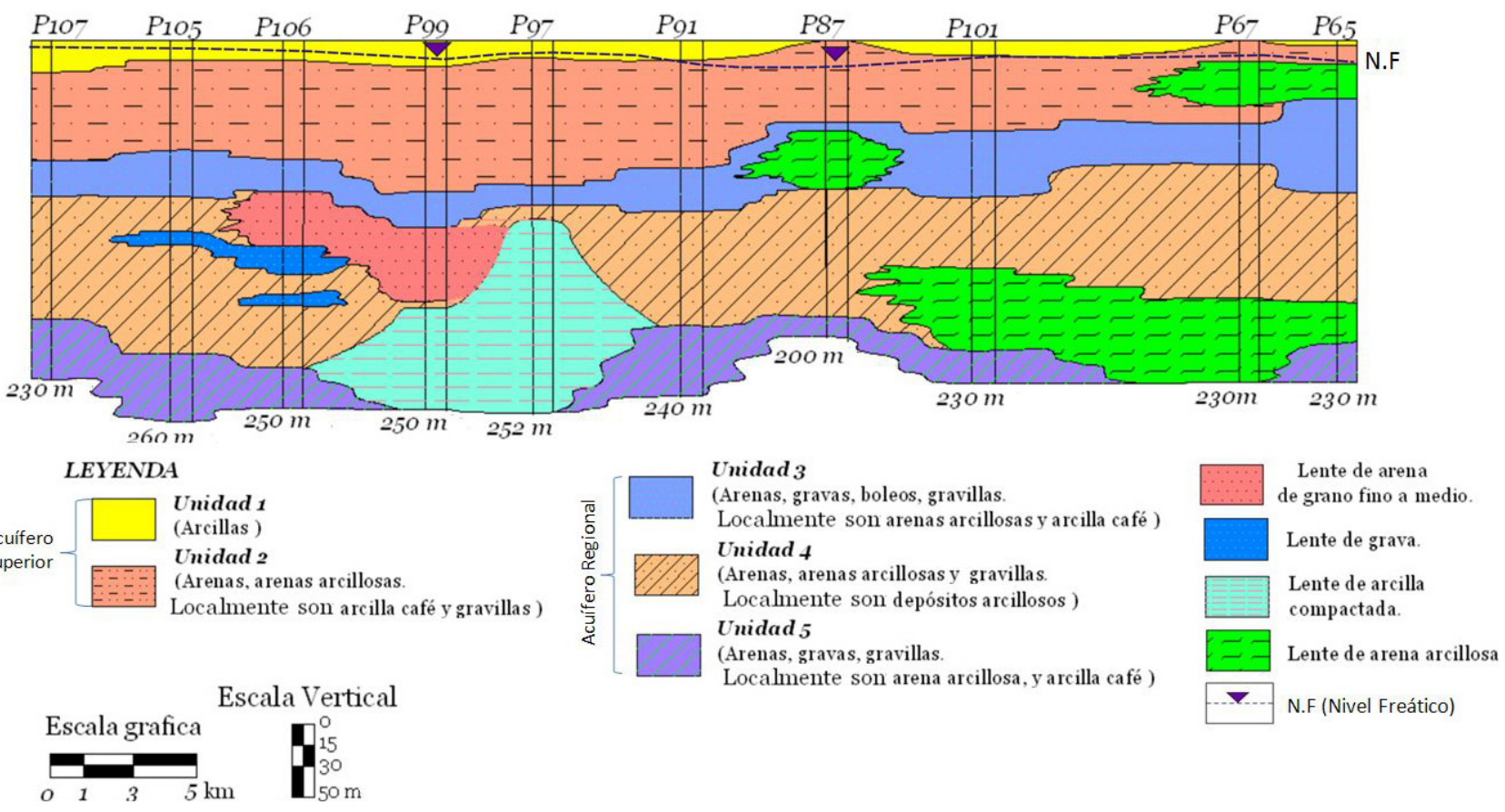

Figura 8. Sección 3 perpendicular a la línea de costa orientada SW-NE.

4.3.2.4. Sección 4. Esta sección de $20 \mathrm{~km}$ de longitud, orientada SW-NE, está compuesta por las unidades hidroestratigráficas 1, 2, 3, 4, y 5 (Figura 9). La Unidad 1 presenta espesores entre 5 y $25 \mathrm{~m}$. La Unidad 2 presenta espesores entre 26 y $44 \mathrm{~m}$, incluyendo un lente de gravas de $12 \mathrm{~m}$ de espesor. La Unidad 3 en esta sección presenta espesores entre 31 y $70 \mathrm{~m}$. La Unidad 4 presenta espesores mínimos entre 16 y 50 m y máximos perforados de 138 $\mathrm{m}$, incluyendo lentes de grava con espesores entre 15 y 20 $\mathrm{m}$. La Unidad 5 presenta un espesor máximo perforado de $127 \mathrm{~m}$. En esta sección se puede observar el basamento de la cuenca, constituido por rocas graníticas y volcánicas (riolita), a profundidades entre 100 y $164 \mathrm{~m}$.

4.3.2.5. Sección 5. Esta sección de $52 \mathrm{~km}$ de longitud, orientada NW-SE (paralela a la línea de costa), está compuesta por 5 unidades (Figura 10). La Unidad 1 presenta 


\section{SW Sección 4 perpendicular a la costa}

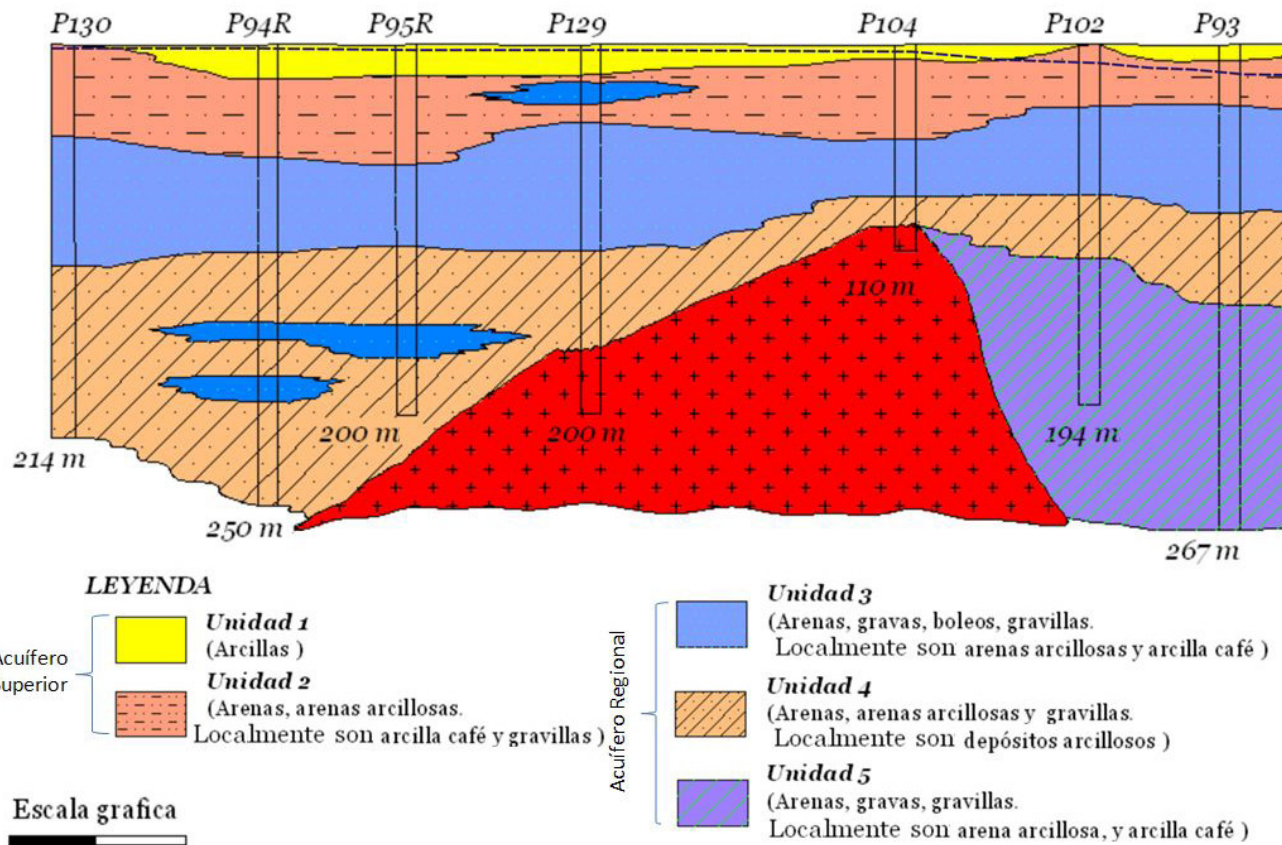

Figura 9. Sección 4 perpendicular a la línea de costa, orientada SW-NE.

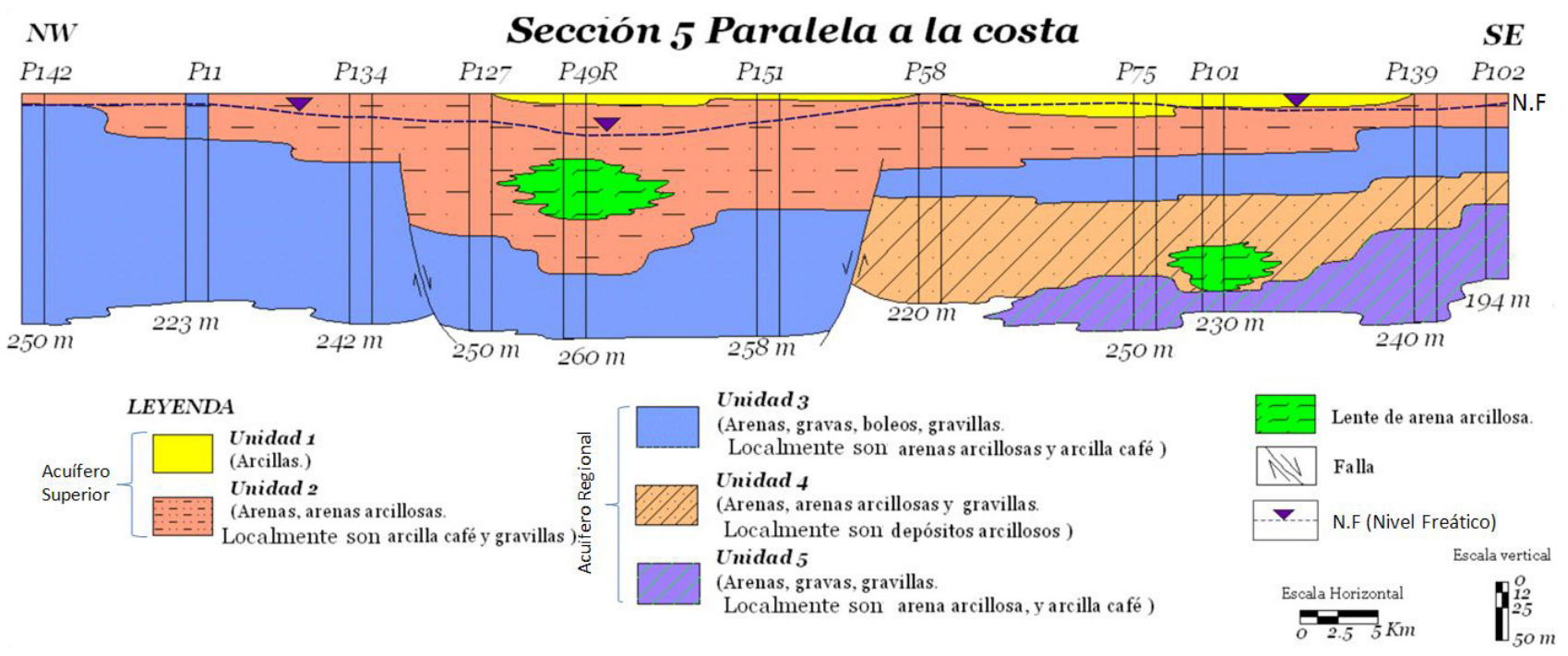

Figura 10. Sección 5 paralela a la línea de costa, orientada NW-SE.

espesores entre $<2$ y $35 \mathrm{~m}$. La Unidad 2 presenta espesores entre 12 y $150 \mathrm{~m}$, incluyendo un lente de arenas arcillosas de $65 \mathrm{~m}$ de espesor. La Unidad 3 presenta espesores perforados entre 15 y $238 \mathrm{~m}$. La Unidad 4 presentas espesores perforados entre 33 y $133 \mathrm{~m}$, incluyendo un lente de arenas arcillosas de $50 \mathrm{~m}$ de espesor. La Unidad 5 está constituida principalmente por arenas, gravas, gravillas, arenas arcillosas y arcillas, con espesores perforados entre
22 y $100 \mathrm{~m}$. La Unidades 2, 3 y 4 son desplazadas por dos fallas con orientación $\sim \mathrm{N}-\mathrm{S}$ en el centro de la sección y que produjeron un amplio graben entre los pozos P134 y P158 (Figura 10).

4.3.2.6. Sección 6. Esta sección, orientada NW-SE, con $57 \mathrm{~km}$ de longitud, está compuesta por 5 unidades hidroestratigráficas. La Unidad 1 presenta espesores < 
$2 \mathrm{~m}$. La Unidad 2 presenta espesores entre 38 y $106 \mathrm{~m}$, incluyendo lentes de gravas con un espesor de $\sim 15 \mathrm{~m}$ y lentes de arenas arcillosas de $30 \mathrm{~m}$ de espesor, debidos probablemente a la migración del antiguo cauce del río Yaqui. La Unidad 3 presenta espesores perforados entre $60 \mathrm{y}$ 179 m. La Unidad 4 presenta espesores perforados entre 60 y $132 \mathrm{~m}$, incluyendo un lente grueso de arcillas compactadas con un espesor de $166 \mathrm{~m}$. La Unidad 5 sólo se encuentra en el pozo P103 y presenta un espesor máximo perforado de $50 \mathrm{~m}$. El basamento consiste de rocas volcánicas (riolitas) y se encuentra a una profundidad de $170 \mathrm{~m}$. Las Unidades 2, 3 y 4 son desplazadas por dos fallas con orientación $\sim \mathrm{N}-\mathrm{S}$ en el centro de la sección, que produjeron un graben entre los pozos P47 y P56 (Figura 11).

4.3.2.7. Sección 7. Esta sección, orientada NW-SE, de
$66 \mathrm{~km}$ de longitud, está constituida por las unidades hidroestratigráficas 1, 2, 3, 4 y 5 (Figura 12). La Unidad 1 presenta espesores entre $<2$ y $15 \mathrm{~m}$. La Unidad 2 presenta espesores entre 2 y $138 \mathrm{~m}$, y presenta lentes de gravas con espesores entre 16 y $8 \mathrm{~m}$, probablemente debido a la migración del antiguo cauce del río Yaqui. La Unidad 3 presenta espesores perforados entre 75 y $222 \mathrm{~m}$, y contiene lentes de grava en la porción SE de la sección. La Unidad 4 contiene espesores perforados entre 80 y $132 \mathrm{~m}$, incluyendo un pequeño lente de grava de $14 \mathrm{~m}$ de espesor. La Unidad 5 sólo se observó en el pozo 107 y presenta un espesor mínimo perforado de $46 \mathrm{~m}$. Las Unidades 2, 3 y 4 son desplazadas por dos fallas orientadas $\sim \mathrm{N}-\mathrm{S}$ en el centro de la sección, y que produjeron un pequeño graben entre los pozos P29 y P33 (Figura 12).

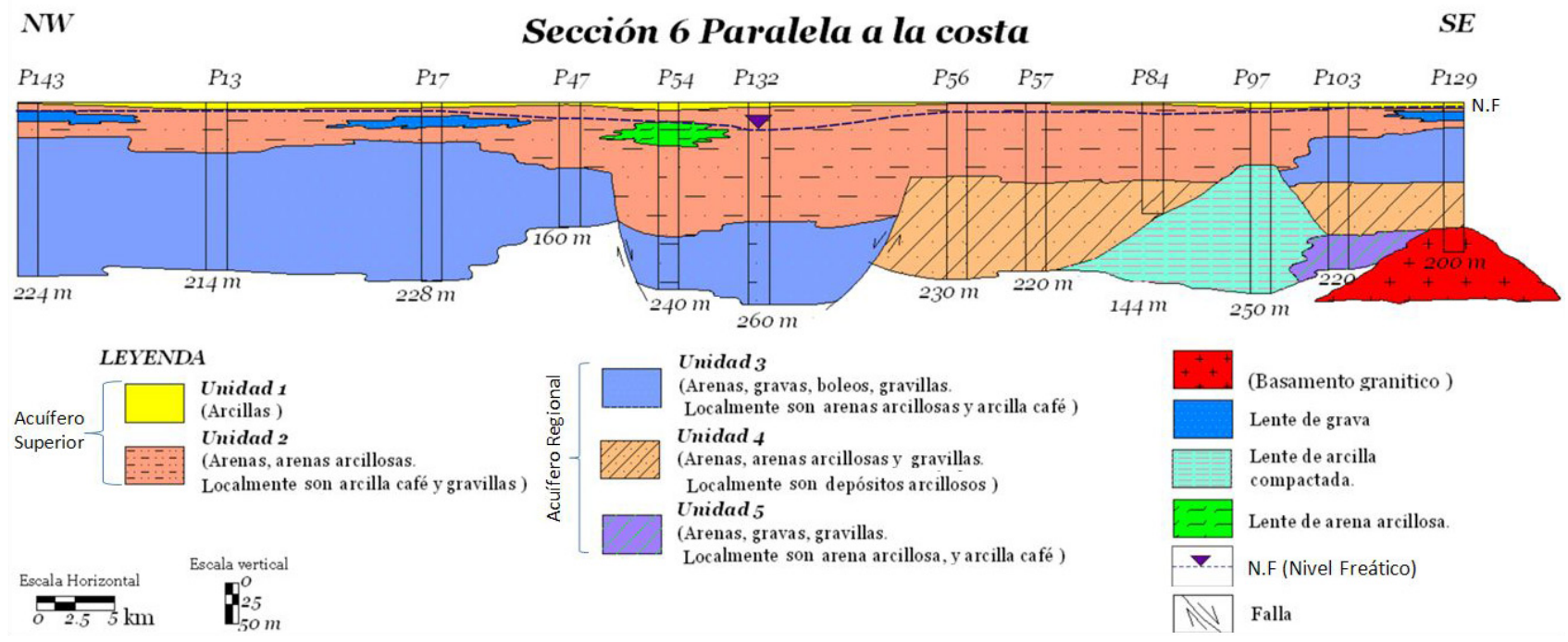

Figura 11. Sección 6 paralela a la línea de costa orientada NW-SE.

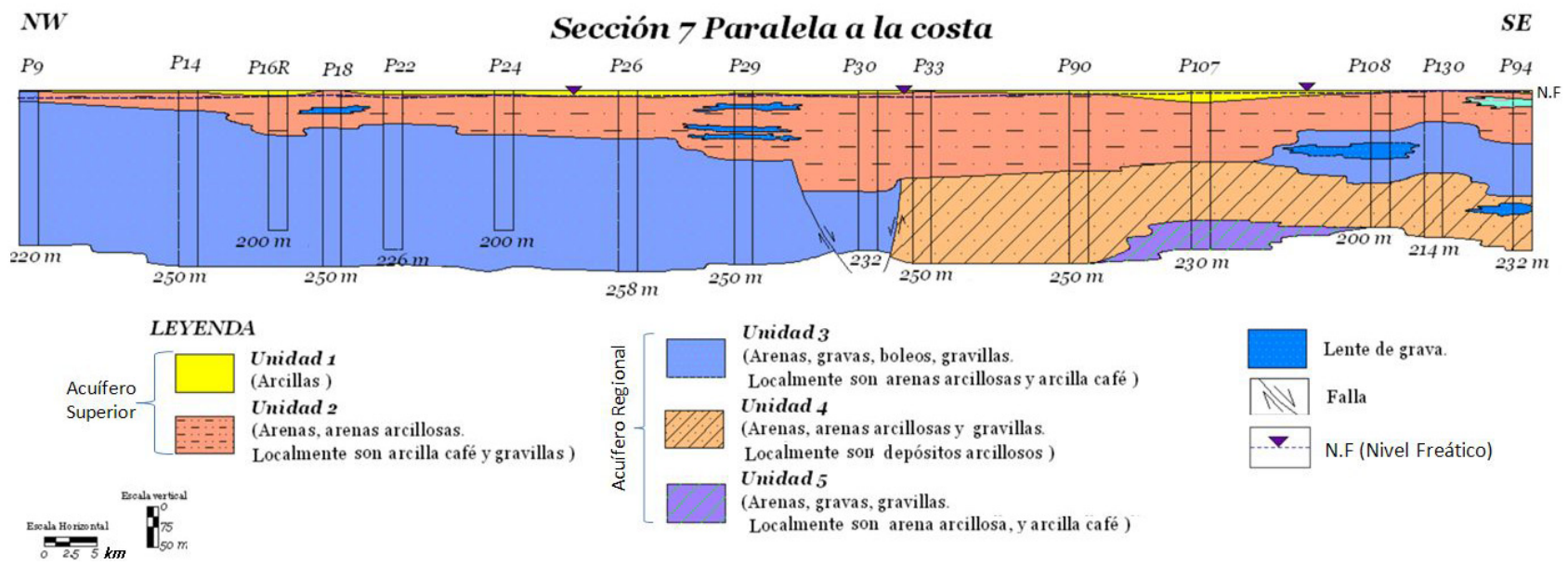

Figura 12. Sección 7 paralela a la línea de costa orientada NW-SE. 


\section{Conclusiones}

Debido a que no existe una definición ampliamente aceptada para el establecimiento de unidades hidroestratigráficas, en el presente trabajo éstas se definieron usando las características litológicas de los sedimentos recuperados en los pozos y su conductividad hidráulica y, con base en lo propuesto por Poehls y Smith (2009), asociando los valores hidráulicos y geoeléctricos a cada tipo de litología.

Por otro lado, tampoco existen metodologías para el establecimiento de este tipo de unidades, por lo que en este trabajo se propone una metodología para la definición de unidades hidroestratigráficas en acuíferos granulares y se presenta como un ejemplo el caso del acuífero del valle del río Yaqui. Dicha metodología incluye: (1) recopilación de mapas y bases topográficas, imágenes e información geológica del área de estudio, (2) análisis de la litología y granulometría de los pozos, además de datos piezométricos y pruebas de bombeo, así como la homogenización de las unidades litológicas establecidas para cada pozo, (3) elaboración de secciones litológicas por medio de correlaciones entre pozos, (4) asignación de propiedades geoeléctricas y de resistividades (si se dispone de información) a las unidades, (5) asignación a cada unidad hidroestratigráfica del valor de conductividad hidráulica obtenido en la interpretación de las pruebas de bombeo, (6) elaboración de secciones hidroestratigráficas, y (7) elaboración de un modelo hidrogeológico tridimensional esquemático (Figura 13).

El análisis de la información gravimétrica, de cortes litológicos de pozos y correlaciones litoestratigráficas indican claramente que el subsuelo del valle del río Yaqui está conformado por un graben tectónico con orientación $\mathrm{N}-\mathrm{S}$, otro por debajo del arroyo Cocoraque con orientación SW-NE, y un tercero ubicado en la porción NNW del área de estudio, por debajo del cauce actual del río Yaqui (Figura 3).

Las secciones hidroestratigráficas en la zona del valle del río Yaqui nos muestran cómo varían los espesores de las Unidades 2 y 3 que, de acuerdo con su litología, son las que contienen más materiales granulares en el acuífero,

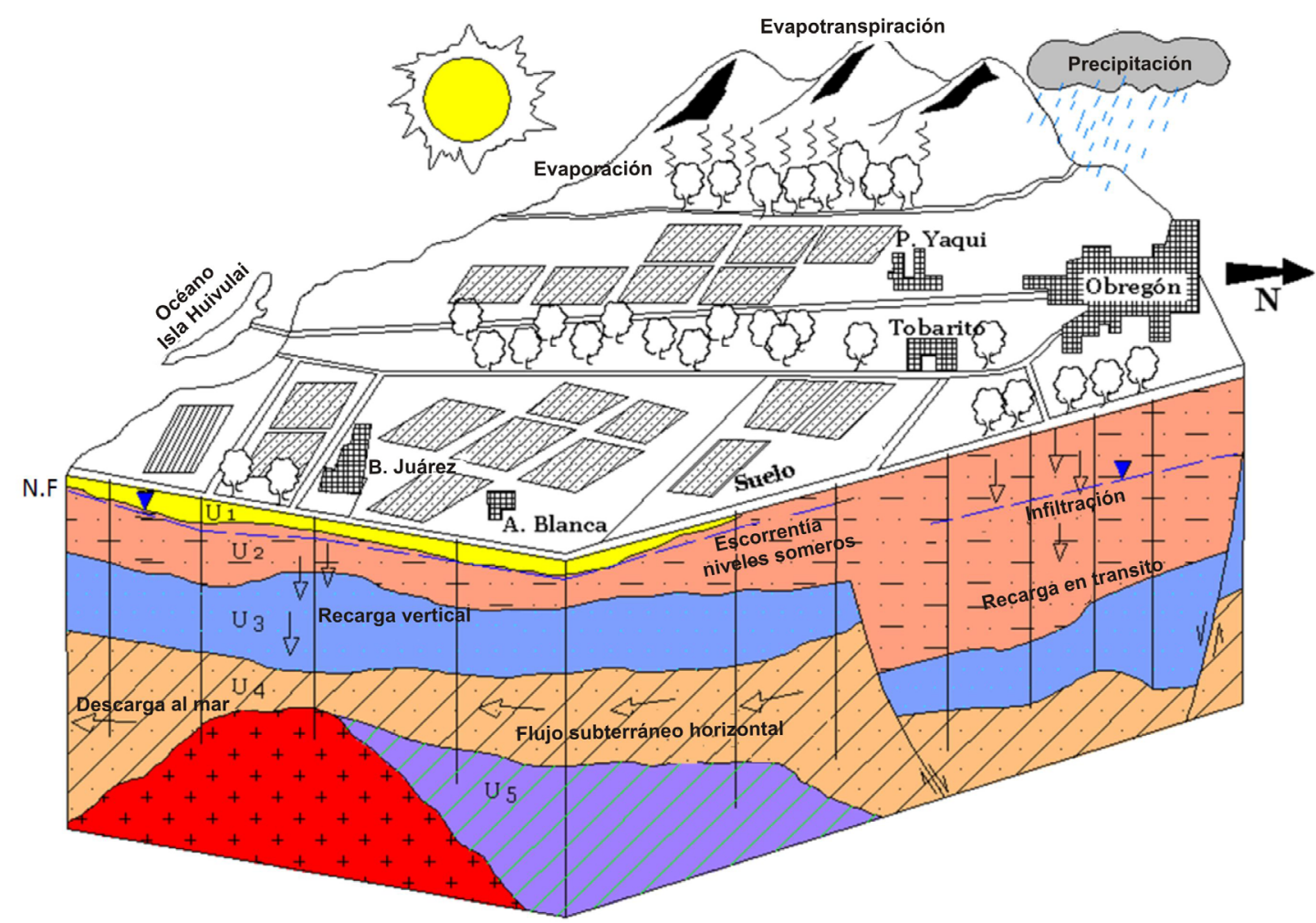

LEYENDA

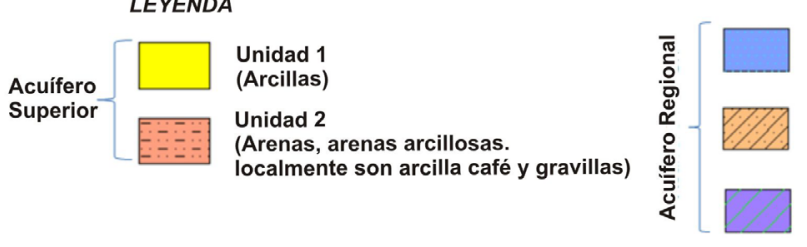

Unidad 3

(Arenas, gravas, boleos, gravillas.

localmente son arenas arcillosas y arcilla café)

Unidad 4

(Arenas, arenas arcillosas y gravillas

localmente son depósitos arcillosos)

Unidad 5

(Arenas, gravas y gravillas.

localmente son arenas arcillosas y arcilla café)

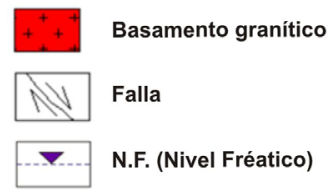

Figura 13. Bloque tridimensional que muestra las unidades hidroestratigráficas presentes en el acuífero del valle del río Yaqui. 
alcanzando un promedio de $200 \mathrm{~m}$ de espesor. Este espesor se amplía en la parte media del valle a $250 \mathrm{~m}$ debido a la generación de fallas en el basamento, que produjeron un graben tectónico y, como consecuencia, un relleno sedimentario más potente de las Unidades 2 y 3 (Figuras 6, 7, 10 y 11).

En las secciones 5, 6 y 7 se presentan variaciones litológicas hacia el SE, como lentes de arcillas compactadas y la presencia de la arenas, gravas y gravillas (Unidad 5), por lo que esta zona es la de mayor variabilidad en los patrones de sedimentación dentro del área de estudio. Ello, probablemente debido al alto topográfico del basamento existente. Por encima, se presentan lentes arcillosos de grandes espesores (Figura 11).

El valle del río Yaqui se encuentra en una región tectónicamente activa, resultante del proceso de apertura del Golfo de California. El relleno de sedimentos de las cuencas resultantes constituye el sistema acuífero del valle. Esta área forma parte de una compleja distribución de planicies de origen fluvio-aluvial y deltaica con dos acuíferos: uno superior de tipo libre (freático) en la zona próxima a la superficie, constituido por las Unidades 1 y 2, y un acuífero regional constituido por las Unidades 3,4 y 5 , de amplia extensión, espesor y composición variable y cuyo tipo varía localmente de libre, a semiconfinado y confinado.

\section{Agradecimientos}

El presente estudio fue realizado dentro del convenio de colaboración entre la Universidad de Sonora y el Distrito de Riego del río Yaqui para llevar a cabo el proyecto "Estudio de actualización geohidrológica del acuifero "Valle del Yaqui" Municipio de Cajeme, Sonora". Agradecemos al Dr. Lener Sequeira por sus valiosas correcciones y sugerencias, así como al revisor anónimo por sus valiosos comentarios, los cuales sirvieron para mejorar de manera sustancial este manuscrito.

\section{Referencias}

Ansaldo-Leyva, J.C., 1999, Estimación de la aportación media por infiltración del canal principal bajo en la sección de la batería de pozos que abastecen a Guaymas - Empalme en el acuífero del valle aluvial del río Yaqui: Ciudad Obregón, Sonora, México, Instituto Tecnológico de Sonora, Tesis de Maestría, $58 \mathrm{p}$.

Antuna-Ibarra, I., Kretzschmar, T., 2004, Desarrollo hidrogeológico con énfasis en la hidrogeoquímica del acuífero de La Misión, Ensenada, Baja California, México en XXXIII congreso AIH, Groundwater Flow understanding from local to regional scales: Zacatecas, México.

Badan, A., Kretzschmar, T., Espejel, I., Cavazos, T., D’Acosta, H., Vargas, P., Mendoza, L., Leyva, C., Arámburo, G., Daesslè, W., Ahumada, B., 2006, Hacia un plan de manejo del agua en Valle de Guadalupe, Baja California, en Memorias del II Seminario Internacional de Vitivinicultura: Ensenada, Baja California, México, INIFAP, 45-64.

Canales, A.G., Díaz, S., 1986, Planeación del uso conjunto de aguas superficiales y subterráneas en el valle del Yaqui: Ciudad Obregón, Sonora, México, Instituto Tecnológico de Sonora, Informe técnico,
$180 \mathrm{p}$.

Copeland, R., Upchurch, S.B., Scott, T.M., Kromhout, C., Arthur, J., Means, G., Rupert, P., Bond, P., 2009, Hydrogeological Units of Florida: Tallahasee, Florida, Florida Geological Survey Special Publication 28, $32 \mathrm{p}$.

Fetter C.W., 1994, Applied Hydrogeology: Nueva Jersey, EUA, Prentice Hall, $691 \mathrm{p}$.

Flores-Tapiz, R.I., 2001, La calidad del agua para riego agrícola de pozos profundos del valle del Yaqui con énfasis en toxicidad de Boro, Cloruros y Sodio: Ciudad Obregón, Sonora, México, Instituto Tecnológico de Sonora, Tesis de Maestría, 96 p.

García-Cortés, J.A., Siqueiros-López, C., 2002, Carta Geológico-Minera Guaymas G12-2, 1:250000: Pachuca, Hidalgo, México, Servicio Geológico Mexicano, 1 mapa.

Geólogos Consultores Asociados, S.A., 1979, Estudio de las condiciones geohidrológicas, sitios adecuados de perforación y delimitación de acuíferos terciarios de los valles intermontanos de Yécora, Río Chico, Los Cedros, Jincore y Cocoraque, Estado de Sonora: Hermosillo, Sonora, México, Gobierno del estado de Sonora-Secretaría de Agricultura y Recursos Hidráulicos, Informe técnico, 206 p.

Gómez-Aldama, O.R., 1992, Un modelo de programación por redes para planear la operación del uso conjunto de aguas superficiales y subterráneas en el valle del Yaqui, Sonora: Ciudad Obregón, Sonora, México, Instituto Tecnológico de Sonora, Tesis de Maestría, 122 p.

Grijalva-Noriega, F.J., Roldán-Quintana, J., 1998, An overview of the Cenozoic tectonic and magmatic evolution of Sonora, northwestern Mexico: Revista Mexicana de Ciencias Geológicas, 15, 145-156.

Gutiérrez-Heredia, R.E., 2004, Evolución Geomorfológica del valle del Yaqui: Hermosillo, Sonora, México, Universidad de Sonora, Departamento de Geología, Tesis de Licenciatura, $101 \mathrm{p}$.

Hawley, J.W., Kennedy, J.F., Creel, B.J., 2001, The Mesilla Basin aquifer system of New Mexico, West Texas, and Chihuahua-An overview of its hydrogeologic framework and related aspects of groundwater flow and chemistry, en Mace, R.E., Mullican, W.F.III, Angle, E.S. (eds.), Aquifers of West Texas: Texas water development board, Report 356, 76-99.

Herrera-Carbajal, S., Villalba-Atondo, A.I., Molinar-Tabares, M.E, 2007, Modelación hidrogeológica y evaluación de la sustentabilidad del acuífero transfronterizo del Río San Pedro en Sonora, México: Revista Latinoamericana de Recursos Naturales, 3, 21-30.

ICATEC Consultores, 1970, Estudio geohidrológico del valle del Yaqui, Sonora (Distrito de Riego 041): Hermosillo, Sonora, México, Secretaría de Recursos Hidráulicos, Informe Interno para la Dirección de Aguas Subterráneas, 140 p.

Instituto Tecnológico de Sonora, 1996, Planeación del uso conjunto de aguas superficiales y subterráneas en el valle del Yaqui, Sonora: Ciudad Obregón, Sonora, México, Instituto Tecnológico de SonoraConsejo Nacional de Ciencia y Tecnología, Informe Técnico IX, $190 \mathrm{p}$.

Instituto Tecnológico de Sonora, 2000, Estudio de disponibilidad y actualización hidrogeológica en los acuíferos de los valles de: El Yaqui, El Mayo, Boca Abierta y Guaymas, Sonora: Ciudad Obregón, Sonora, México: Comisión Nacional del Agua-Gerencia de Aguas Subterráneas, Informe Técnico, 205 p.

Lozano-Cota, L.M., 1992, Un modelo de programación lineal para la planeación del uso conjunto de aguas superficiales y subterráneas en el valle del Yaqui, Sonora: Ciudad Obregón, Sonora, México, Instituto Tecnológico de Sonora, Tesis de Maestría.

Martínez-Uribe, M.E., 1999, Caracterización hidrogeológica de las formaciones volcánicas y sedimentarias en el valle de Boca Abierta, Sonora: Ciudad Obregón, Sonora, México, Instituto Tecnológico de Sonora, Tesis de Maestría, $90 \mathrm{p}$.

Maxey, G.B., 1964, Hydrostratigraphic units: Journal of Hydrology, 2, 124-129.

Minjarez-Sosa, J.A., Montaño-Jiménez, T., Ochoa-Granillo, J.A., GrijalvaNoriega, F.J., Ochoa-Landín, L.H., Herrera-Urbina, S., GuzmánEspinosa, J.B., Mancilla-Gutiérrez, A.A., 2002, Carta Geológica Minera Ciudad Obregón G12-3, Escala 1:250000: Pachuca, Hidalgo, México, Servicio Geológico Mexicano, 1 mapa. 
Monreal, R., Castillo, J., Rangel, M., Morales, M., Oroz, L.A., Valenzuela, H., 2001, La intrusión salina en el acuífero de la costa de Hermosillo, Sonora, en Corona-Esquivel, R., Gómez-Godoy, J., (eds.), Acta de sesiones de la XXIV convención internacional de la asociación de ingenieros de minas metalurgistas y geólogos de México A.C.: Acapulco, Guerrero, México, 93-98.

Monreal, R., Rangel-Medina, M., Minjarez-Sosa, I., Castillo-Gurrola, J., Morales-Montaño, M., 2003, Estudio de actualización geohidrológica del acuífero valle del Yaqui, Municipio de Cajeme, Sonora: Hermosillo, Sonora, México, Universidad de Sonora, Informe Técnico, $146 \mathrm{p}$.

National Research Council (NRC), 1995, Mexico City's water supply. Improving the outlook for sustainability: Washington, D.C., National Research Council-Academia de la Investigación Científica, A.C.Academia Nacional de Ingeniería, A.C.-National Academy Press, $216 \mathrm{p}$.

Navarro-Ibarra, L.A., 2001, Modelo de optimización-simulación para generar políticas de extracción en el acuífero del valle del Yaqui, Sonora: Ciudad Obregón, Sonora, México, Instituto Tecnológico de Sonora, Tesis de Maestría, $87 \mathrm{p}$.

North American Commission on Stratigraphic Nomenclature (NACSN), 2005, North American Stratigraphic Code, American Association of Petroleum Geologists Bulletin, 89, 1547-1591.

Paula e Silva de, F., Chang, H.K., Caetano-Chang, M.R., 2005, Hydrostratigraphy of the Bauru Group São Paulo State, Brazil: Águas Subterrâneas, 19, 19-36.

Poehls, D.J., Smith, G.J., 2009, Encyclopedic dictionary of hydrogeology: Amsterdam, Academic Press, 517 p.

Salvador, A., 1994, International stratigraphic guide: Boulder, Colorado, EUA, International Union of Geological Sciences - Geological Society of America, $214 \mathrm{p}$.
Sanz, D., Gómez-Alday, J.J., Castaño, S., De las Heras, J., Martínez-Alfaro, P.E., 2009, Hydrostratigraphic framework and hydrogeological behaviour of the Mancha Oriental System (SE Spain): Hydrogeology Journal, 17, 1375-1391.

Seaber, P.R., 1986, Definition of hydrostratigraphic units: 2nd Annual Symposium on Florida Hydrogeology, Northwest Florida Water Management District Public Information Bulletin 82, 25-26.

Seaber, P.R., 1988, Hydrostratigraphic Units, en Back, W., Rosenshein, J.S., Seaber, P.R., (eds.), Hydrogeology: Boulder, Colorado, Geological Society of America, 9-14.

Técnicas Geológicas y Mineras, 1996, Estudio para el diseño de redes de monitoreo de los acuíferos de los valles de: El Yaqui, Hermosillo y Caborca, en el Estado de Sonora: Hermosillo, Sonora, México, Informe Técnico, $179 \mathrm{p}$.

Técnicas Geológicas y Mineras, 1997, Actualización de mediciones piezométricas de los acuíferos reactivados en 1996 (PROMMA), en los Estados de Sonora y Chihuahua: Hermosillo, Sonora, México, Informe Técnico, $146 \mathrm{p}$.

Verduzco, H.M., 2002, Estudio de la calidad del agua subterránea y vulnerabilidad a la contaminación del área de Tamazula: Guasave, Sinaloa, México, CIIDIR-IPN, Unidad Sinaloa, Tesis de Maestría, $106 \mathrm{p}$.

Zapuche-Moreno, I. C., 2000, Hidrogeoquímica de la franja costera del acuífero del valle del yaqui, Sonora: Ciudad Obregón, Sonora, México, Instituto Tecnológico de Sonora, Tesis de Maestría, 125 p.

Manuscrito recibido: Septiembre 15, 2009.

Manuscrito corregido recibido: Agosto 5, 2010.

Manuscrito aceptado: Septiembre 7, 2010. 